\title{
Best Vocabulary Practices to Support Mathematics in the Age of Common Core Standards
}

\author{
Shere Salinas \\ Department of Curriculum \& Instruction \\ Corpus Christi Independent School District, United States \\ E-mail: shere.salinas@ccisd.us \\ Evan Ortlieb \\ Assistant Professor in Curriculum \& Instruction \\ Texas A\&M University - Corpus Christi, United States \\ E-mail: evan.ortlieb@tamucc.edu
}

\author{
Received: August $5 \quad$ Accepted: November $9 \quad$ Published: December 1, 2011 \\ doi:10.5296/jse.v1i1.844 URL: http://dx.doi.org/10.5296/jse.v1i1.844
}

\begin{abstract}
Mathematics can resemble a foreign language with its seemingly cryptic symbols and unknown terminology, challenging students' ability to read, write, and communicate clearly; especially for English Learners. Some strategies that good readers use such as clues are rarely useful strategies for interpreting unknown word meanings (Roe, Stoodt-Hill, \& Burns, 2004); a series of best practices in vocabulary specifically geared towards the field of mathematics is warranted. An examination of existing bodies of research ensued to identify the underlying difficulties related to vocabulary acquisition in mathematics, classification of vocabulary words, and specific vocabulary instructional strategies that support critical thinking skills necessary for mathematical knowledge formation and communication. This study aimed to equip mathematics teachers with a better understanding of vocabulary acquisition and how to effectively teach vocabulary to aid in mastery of skill, understanding, and communication of mathematical principles.
\end{abstract}

Keywords: vocabulary, mathematics, content area, schema theory, strategies 


\section{Introduction}

Vocabulary instructional practices need to be revisited with the growing population of English Learners. According to the National Clearinghouse for English Language Acquisition (2011), during the 2008-2009 school year, there were 5.3 million English Learners in schools pre-kindergarten through grade 12 . This constitutes approximately 10.8 percent of the total public school enrollment in the United States; this is an increase of 51\% since 1998. California leads the country with approximately 1.5 million English Learners in public school. Texas comes in second with just over 700000, and Florida in third with approximately 250000 English Learners in public school (NCELA, 2011). What these numbers call attention to is the immediate need classroom teachers have of enhancing the instructional practices for mathematics vocabulary for diverse classrooms in the $21^{\text {st }}$ century.

Mathematics can resemble a foreign language with its seemingly cryptic symbols and unknown terminology, challenging students' ability to read, write, and communicate clearly. This system of language combines written words with symbols to express complex ideas. Mathematical writing requires precision in word usage, thus accentuating the need for deep vocabulary understanding for student success. Unfortunately, textbooks are generally denser per line and on each page than other content areas (Roe, Stoodt-Hill, \& Burns, 2004), leading the reader to comprehend less and less without a steady dose of explicit vocabulary instruction in the mathematics classroom (Barton \& Heidema, 2002). Some strategies that good readers use such as clues are rarely useful strategies for interpreting unknown word meanings (Roe, Stoodt-Hill, \& Burns, 2004); a series of best practices in vocabulary specifically geared towards the field of mathematics is warranted.

An examination of existing bodies of research ensued to identify the underlying difficulties related to vocabulary acquisition in mathematics, classification of vocabulary words, and specific vocabulary instructional strategies that support critical thinking skills necessary for mathematical knowledge formation and communication. Practices and strategies that support other content area learning were found but omitted from this systematic literature review. This study aimed to equip mathematics teachers with a better understanding of vocabulary acquisition and how to effectively teach vocabulary to aid in mastery of skill, understanding, and communication of mathematical principles. This is particularly salient in the new era of Common Core Standards (2010), where requirements call for students to be provided multiple opportunities to listen, read, write, speak, reflect, and demonstrate mathematical ideas.

\section{Theoretical Framework}

This study is grounded in the schema theory of learning, rooted in the organization of knowledge as opposed to simple behaviorism (Wiswell \& Wells, 2004; Young \& Wilson, 2002). Schema is a cognitive framework founded when previous knowledge is realized (Goldstone \& Son, 2005; Zheng et al., 2008). If applied from an early age, students develop a model for life-long problem-solving skills limited only by creativity and commitment that has the potential to produce more efficient learning (Siraj-Blatchford \& Siraj-Blatchford, 2002; Young-Jin, 2010). Schemas constantly grow, change, and are skewed by misconceptions; 
rigid schemas, where testing understanding is bypassed, are less flexible to change (SIL, 1999; Wiswell \& Wells, 2004).

The misapplication of the schema theory of learning can limit life-long learning. In the classroom, teachers activate prior knowledge, known also as generic knowledge; conversely, text knowledge is a term that refers to new knowledge. Introducing text knowledge without first activating generic knowledge, in this case through vocabulary instruction, leaves the teacher unable to differentiate between a student's old schema and a student's new schema (Lee, 2010). Most importantly though, the schema theory of learning is significant because scaffolding vocabulary development reduces the influx of new content to produce a new schemata required to increase comprehension (Young-Jin, 2010).

\section{Difficulties with Reading Comprehension in Mathematics}

Students with a gap in word knowledge face difficulties in reading comprehension and also content learning (Flood, Lapp, \& Fisher, 2003). "Vocabulary is as unique to a content area as fingerprints are to a human being. A content area is distinguishable by its language, particularly the technical terms that label the concepts undergirding the subject matter" (Vacca \& Vacca, 2008, p. 2).Understanding vocabulary terms and phrases are related to the learner's ability to comprehend new information (Paynter, Bodrova, \& Doty, 2005). This is especially important for English Learners (ELs) while they are developing the cognitive academic language proficiency necessary to be successful in content areas (Cummins, 1998).

High stakes assessments require students to read and respond to word problems filled with upper level vocabulary, necessitating that students are proficient readers, comprehending content to perform the necessary mathematics. Hence, these assessments are as much a test of reading comprehension as they are of mathematics knowledge. Mathematical word problems have grown in length and complexity with each subsequent generation of state mandated assessments (Daro, Stancavage, Ortega, DeStafano, \& Linn, 2007).

The following are problems from the exit level assessment. The first is from the Texas Educational Assessment of Minimum Skills (TEAMS) administered from 1986-1990 (see Figure 1). The crucial vocabulary word understanding needed to answer this question is "least."In the Texas Assessment of Academic Skills (TAAS) administered from 1990-2002 example (see Figure 2), the essential vocabulary knowledge needed to answer this question is per and the phrase how much money. The term pupils would aid the understanding; however, the problem could be solved without it.

Figure 3 is from the Texas Assessment of Knowledge and Skills (TAKS) first administered in 2003 and is being phased out with the 2011-2012 school year.

The essential vocabulary needed to answer the question was percent, total, paper, and solid waste. The word municipal is helpful to know but is not necessary to answer the question. Not knowing the word may confuse some students. The final item is a possible look at what the upcoming State of Texas Assessments of Academic Readiness (STAAR) test will look like. It will be phased in during the 2011-2012 school year. 
The essential vocabulary necessary for solving this problem is correct, description, graph, quadratic, function, intersects, $x$-axis, twice, $y$-axis, and the symbols $\neq,<,>, \sqrt{,} b^{2}$, and $f(x)$. The items have progressively increased in essential vocabulary necessary to solve the problems, increased in the usage of more precise mathematical language, and have intensified the usage of mathematical symbols used in combination with words to convey meaning (see Figure 4).

\section{Classification of Vocabulary Found in Mathematics}

There are a variety of classification systems for mathematical vocabulary. Vacca and Vacca (2008) identify three types of vocabulary that are found in textbooks. The first type is general vocabulary which largely consists of everyday words that are commonly used. The second type is special vocabulary.It is made up of words from general vocabulary that have specialized meanings in particular content areas. The third type is technical vocabulary. This type consists of words that have usage and application in only a particular field of study.Monroe and Panchyshyn (1995) further refined the categories specific to mathematics. They identify four types of mathematical vocabulary; technical, subtechnical, general, and symbolic.

Technical vocabulary consists of words are specific to the content area. They typically are defined by using additional technical terms resulting in a difficult situation for students to truly learn the meaning of this type of vocabulary. Examples of technical vocabulary are words such asquotient, reciprocal, and square root. Subtechnical vocabulary consists of words that have multiple meanings. Terms such as range, degree, face, root, and plane have very specific mathematical meanings. These words may exist within a student's vocabulary but the mathematical meanings may be completely foreign.

General vocabulary consists of words which are typically part of common language. Examples of general vocabulary are liter, gallon, more than, less than, and part of. Symbolic vocabulary, on the other hand, consists of numerals and symbols used in mathematics. For example, $>, \pi, \neq,+, \infty, 23,3.1, \frac{3}{4}$, and $7^{3}$. Other symbols used in mathematics are abbreviations representing units such as $o z, l b$, and $i n$.

Even though there are differing opinions concerning the classification of mathematical vocabulary, what is agreed upon is that highly technical and abstract words need to be taught differently than more common words that have unique meanings in mathematics. These polysemous words exacerbate vocabulary struggles for English Learners (Rojas, 2009).

\section{Uniqueness of Instructional Practices for Mathematics Vocabulary}

Effective instructional practices of content vocabulary words and phrases have been well documented. Marzano, Pickering, and Pollack (2001) suggested five generalizations to guide vocabulary instruction.

1. Students must encounter words in context more than once to learn them. 
2. Instruction in new words enhances learning those words in context.

3. One of the best ways to learn a new word is to associate an image with it.

4. Direct vocabulary instruction works.

5. Direct instruction on words that are critical to new content produces the most powerful learning.

Nagy (1988) suggested integration, repetition, and meaningful use to teach content area vocabulary. It is interesting that there exists a group that does not favor the explicit teaching of vocabulary. The concerns seem to be focused on the number of words in the English language and the relatively small number of words that can be directly instructed each year (Nagy \& Herman, 1987).However, it has been suggested that an analysis of the research makes a strong case for systematic instruction in vocabulary in virtually every grade level (Marzano, Pickering, \& Pollack, 2001).

The limitations of these suggestions are that they were derived from research on general content vocabulary instructional practices. Mathematics vocabulary was not specifically addressed. There is some limited research specifically addressing mathematical vocabulary. For example, Monroe and Panchyshyn (1997) compared definition instruction to usage of graphic organizers with discussion in learning mathematical vocabulary. They found that the latter had a greater effect on learning mathematical vocabulary in a group of fourth graders. Jackson and Phillips (1983) examined possible relationships between vocabulary instruction and improved understanding of ratio and proportion concepts in a group of seventh graders.

An illustration of vocabulary instructional practices not working in mathematics instruction can be seen with context clues. Although many researchers recommend context clues as a recommended strategy to uncover the meaning of unknown words in content areas, this is not practical in mathematics text. Schell (1982) points out that mathematical text are inherently difficult to comprehend because it has "more concepts per word, per sentence, and per paragraph than any other area" (p.544).Examine the following excerpt from Texas Mathematics Course 3 (2008).

Corresponding angles and corresponding sides of congruent polygons are congruent. The two polygons below are congruent. $\angle \mathrm{T}$ corresponds to $\angle \mathrm{L} . \overline{Y V}$ corresponds to $\overline{M P}$. R corresponds

to K.You can write VTRY $\cong \mathrm{PLKM}$. The tick marks in the diagram tell you which sides are congruent. The arcs tell you which angles are congruent. When you name congruent polygons, you must list the corresponding vertices in the same order. (p. 312)

This passage is rich with technical mathematical vocabulary making it exceedingly difficult to use context clues to gain understanding of unknown words. Within the first sentence there are seven important vocabulary words, the meaning of which cannot be determined through other words in that sentence or subsequent sentences. If the reader is unable to determine the meaning of the term corresponding the concept of the relationships within the geometrical figures is lost. The same is true about congruent, vertices, as well as the symbols used for angle, congruency, and side lengths. 


\section{Discussion}

Knowing a concept of a word and being able to use it involves more than memorizing a definition (Nagy \& Herman, 1986; Stahl, 1999). Students need to learn the mathematical concept and develop the appropriate vocabulary during the process. They need to see how the concepts and terminology are related. Words are labels for concepts, and a single concept may require thousands of words to explain it. Knowing the meaning of the precise vocabulary needs to be developed as well. There are several useful instructional tools to consider employing when explicitly teaching mathematical vocabulary when focusing on teaching individual words and fostering word consciousness which are both suggested practices by Graves and Watts-Taffe (2002) and are positioned in the Marzano, Pickering, and Pollack five generalizations to guide vocabulary instruction (2001). These are word walls, graphic organizers, and games.

\section{Word Walls}

This practice incorporates the teaching of individual words and word consciousness. To be effective, word walls need to be more than a decoration on the wall. A word wall is a collection of words or word parts used to help students learn vocabulary. These are more commonly found in elementary classrooms but are finding their way into middle school rooms as well. Word walls serve as a visual cue to aid in the learning of vocabulary. They provide a "word bank" that can be drawn on for verbal or written explanations communicating mathematical understandings. Word walls encourage usage of new vocabulary words by having them prominently displayed. They can be organized by topic, concept, or simply lists. For example proportionality is an overarching concept of middle school. A word wall could be constructed at the beginning of the year with proportionality prominently displayed. During the year ratio, percent, dilations, scale factor, and unit conversions could be added to this wall to not only make the vocabulary highly visible but could show connections of concepts. Each of the words previously mentioned also have supporting terminology that could be displayed. Students may be required to describe or explain their reasoning in problem solving. They could be directed to use the appropriate vocabulary from the word wall in their explanations. The word wall can serve as a focus to the vocabulary discussions in the classroom. The students can take ownership in identifying new terms that could be added to the word wall. Word walls themselves do not teach vocabulary; they are tools to use to capture students' attention, create an atmosphere of word consciousness, and support students while they are learning the new vocabulary. They provide a support for English Language Learners by providing a word bank to draw from when immersing in the communication about mathematics concepts (Green, 1993). They are a wonderful way to begin explicit vocabulary instruction and should be interacted with by both the teacher and the students (Harmon, Wood, Hedrick, Vintinner, \& Willeford, 2009).

\section{Graphic Organizers}

Graphic organizers are another type of tool to employ when explicitly teaching vocabulary. They show the relationships between terms or reveal meanings of words. Two examples are shown here to illustrate the concept. Graphic organizers are powerful tools to support English 
Language Learners. They reduce the language load by displaying information with pictures, phrases, and labels; additionally they are less intimidating visually (Carrier, 2005). The Frayer Model is a graphic organizer that is used to better understand a word and to distinguish its meaning from other words. The student writes the word being studied in the oval (see Figure $5)$.

The student can refer to a resource such as their textbook for a definition. The examples and non-examples can be pictures, graphic images, and/or text that serve to clarify what the word is and is not. The characteristics clarify the uniqueness of the word. A vocabulary diagram also helps clarify a word's meaning (see Figure 6).It includes related words, drawings and examples, synonyms and antonyms, parts, sentence from text using the word, and original sentences the student creates using the word meaningfully.

\section{Conclusion}

It is hoped that this investigation has spurred mathematics teachers to consider and refine these explicit vocabulary instructional practices within their classrooms. This review of existing research has prompted the need for additional research and investigation, the need for professional development intended to support student vocabulary acquisition, particularly when considering the language needs of English Learners, and the impact explicit vocabulary instruction can have on student success in the age of common core standards.

\section{References}

Barton, M., \& Heidema, C. (2002). Teaching reading in mathematics ( $2^{\text {nd }}$ ed.). Aurora, CO: Mid-continent Research for Education and Learning.

Carrier, K. (2005). Key issues for teaching English language learners in academic classrooms. Middle School Journal, 37(2), 4-9.

Charles, R., Mills, D., Illingworth, M., Ramirez, A., McNemar, B., \& Reeves, A. (2008). Texas Mathematics Course 3. Boston, MA: Pearson Prentice Hall.

Common Core State Standards for Mathematics. (2010). Retrieved June 13, 2011, from http://www.corestandards.org/the-standards/mathematics

Cummins, J. (1998, February). Beyond adversarial discourse: Searching for common ground in the education of bilingual students. Paper presented at the meeting of California State Board of Education, Sacramento.

Daro, P., Stancavage, F., Ortega, M., DeStafano, L., Linn, R. (2007). Validity study of the NAEP Mathematics Assessment: Grades 4 and 8. NAEP.

Flood, J., Lapp, D., \& Fisher, D. (2003). Reading comprehension instruction. In J. Flood, D. Lapp, J. R. Squire, \& J. M. Jensen (Eds.), Handbook of research on teaching the English language arts (2nd ed., pp. 931-941). Mahwah, NJ: Lawrence Erlbaum.

Goldstone, R.L. \& Son, J.Y. (2005). The transfer of scientific principles using concrete and idealized simulations. Journal of the Learning Sciences, 14(1), 69-110. 
http://dx.doi.org/10.1207/s15327809j1s1401_4

Graves, M., \& Watts-Taffe, S. (2002). The place of word consciousness in a research-based vocabulary program. In A. Farstrup \& S. J. Samuels (Eds.). What research has to say about reading instruction ( ${ }^{\text {rd }}$ ed., pp. 140-165). Newark, DE: International Reading Association.

Green, J. (1993). The word wall: Teaching vocabulary through immersion. Ontario, Canada: Pippin Publishing Limited.

Harmon, J., Wood, K., Hedrick, W., Vintinner, J., \& Willeford, T. (2009). Interactive word walls: More than just reading the writing on the walls, Journal of Adolescent and Adult Literacy, 52(5), pp. 398-408. http://dx.doi.org/10.1598/JAAL.52.5.4

Jackson, M., \& Phillips, E. (1983).Vocabulary instruction in ratio and proportion for seventh graders. Journal for Research in Mathematics Education, 14, 337-343. http://dx.doi.org/10.2307/748678

Lee, A. (2010). A way of understanding the world of science informational books. The Reading Teacher, 63(5), 424-428. http://dx.doi.org/10.1598/RT.63.5.8

Marzano, R., Pickering, D., \& Pollock, J. (2001). Classroom instruction that works. Alexandria, VA: Association for Supervision and Curriculum Development.

Monroe, E., \& Panchyshyn, R. (1997).Vocabulary considerations for teaching mathematics. Childhood Education, 72, 80-83. Retrieved from http://www.pittsfordschools.org

Nagy, W. (1988). Teaching vocabulary to improve reading comprehension. Newark, DE: International Reading Association.

Nagy, W., \& Herman, P. (1987).Depth and breadth of vocabulary knowledge: Implications for acquisition and instruction. In M. McKeown \& M. Curtis (Eds.), The nature of vocabulary acquisition (pp. 19-36). Hisdale, NJ: Erlbaum.

National Clearinghouse for English Language Acquisition. (2011). The growing numbers of limited English proficient students: 1998/99-2008/09. Retrieved from http://www.ncela.gwu.edu/files/uploads/9/growingLEP_0809.pdf

National Council of Teachers of Mathematics. (2000). Principles and standards for school mathematics. Reston, VA: Author.

Paynter, D., Bodrova, E., \& Doty, J. (2005).For the love of words: Vocabulary instruction that works. San Francisco: CA. Jossey-Bass.

Roe, B., Stoodt-Hill, B., \& Burns, P. (2004).Secondary school literacy instruction: The content areas. Boston, MA: Houghton Mifflin Company.

Rojas, V. (2009). Strategies for success with ELL: A toolkit for teachers. EARCOS Institute, Inc. Retrieved July 13, 2011, from http://www.earcos.org/etc2009/download/ELL_precon.pdf

Schell, V. (1982). Learning partners: Reading and mathematics. The Reading Teacher, 35, 544-548. 


\section{Macrothink}

Journal of Studies in Education

ISSN 2162-6952

2011, Vol. 1, No. 1: E10

SIL International Partners in Language Development. (1999). Retrieved September, 27, 2011 from http://www.sil.org/lingualinks/literacy/ImplementALiteracyProgram/Schema TheoryofLearning.htm

Siraj-Blatchford, J. \& Siraj-Blatchford, I. (2002). Discriminating between schemas and schema in young children's emergent learning of science and technology. International Journal of Early Years Education, 10(3), 205-214. http://dx.doi.org/10.1080/0966976022000044744

Stahl, S. (1999). Vocabulary development. Cambridge, MA: Brookline Books.

Vacca, R., \& Vacca, J. (2008).Content area reading: Literacy and learning across the curriculum. Boston, MA: Pearson Education.

Wiswell, A. K., \& Wells, C. L. (2004). Escaping the tyranny of belief. Paper presented at the Academy of Human Resource Development International Conference (AHRD), 337-343 (Symp. 17-2), Austin, TX.

Young, D.L. \& Wilson, B.G. (2002). Webquests for reflection and conceptual change: Variations on a popular model for guided inquiry. Presented at the Ed-Media Conference, :Denver CO, June 2002, and published in the Ed-Media annual proceedings. Retreived November 5, 2011 from http://carbon.ucdenver.edu/ bwilson/WebQuest/

Young-Jin, L. (2010). Effects of instructional preparation strategies on problem solving in a web-based learning environment. Journal of Educational Computing Research, 42(4), 385-406. http://dx.doi.org/10.2190/EC.42.4.b

Zheng, R. Z., Yang, W., Garcia, D., \& McCadden, E. P. (2008). Effects of multimedia and schema induced analogical reasoning on science learning. Journal of Computer Assisted Learning, 24, 474-482. http://dx.doi.org/10.1111/j.1365-2729.2008.00282.x 


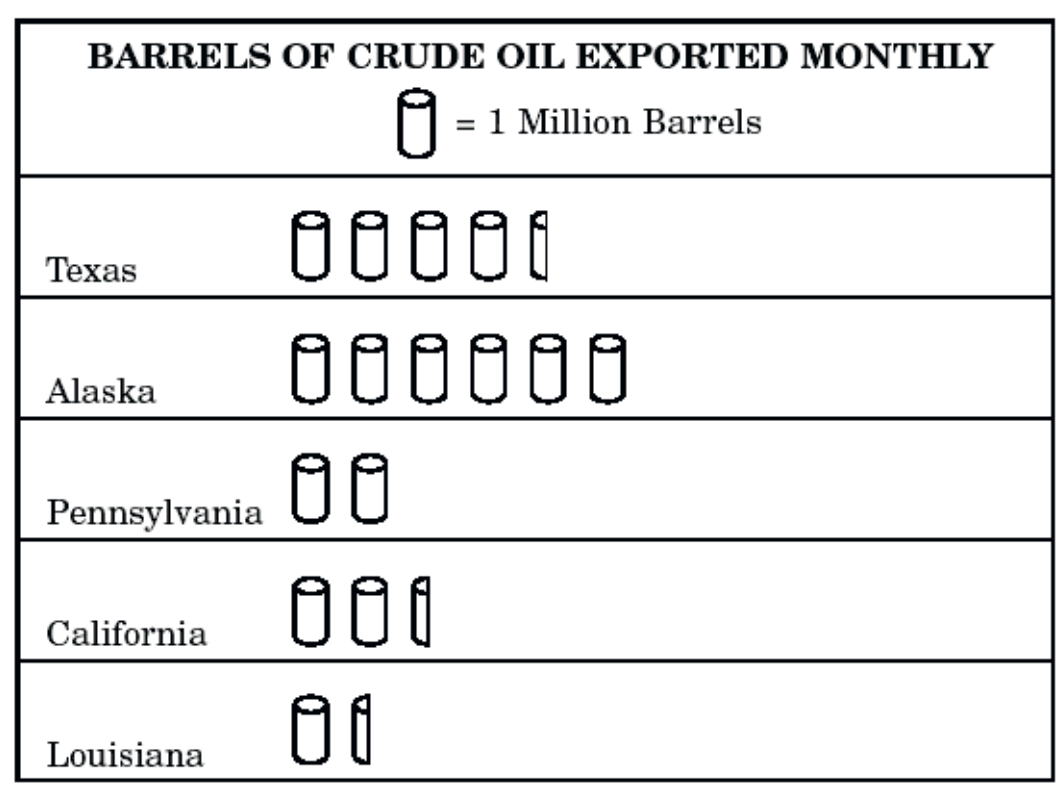

Which state exports the least amount of barrels of crude oil monthly?
A Louisiana
B Texas
C Alaska
D Pennsylvania

Figure 1. Critical vocabulary word understanding needed to answer 


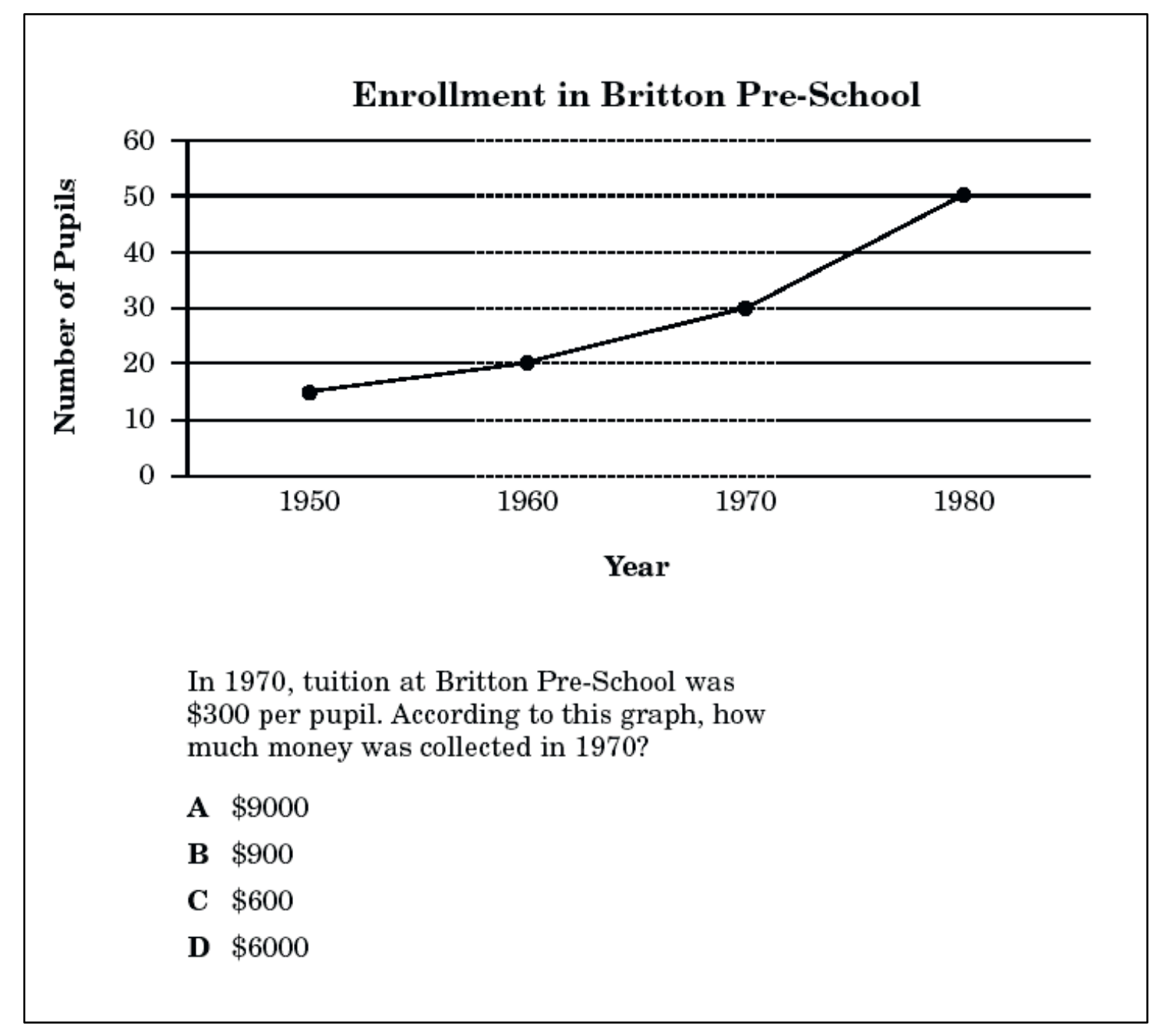

Figure 2. School pupil enrollment of preschoolers 
The graph shows the types and amounts of solid waste produced in the United States in 1988.

$$
\begin{aligned}
& \text { Municipal Solid Waste }-1988 \\
& \text { (millions of tons) }
\end{aligned}
$$

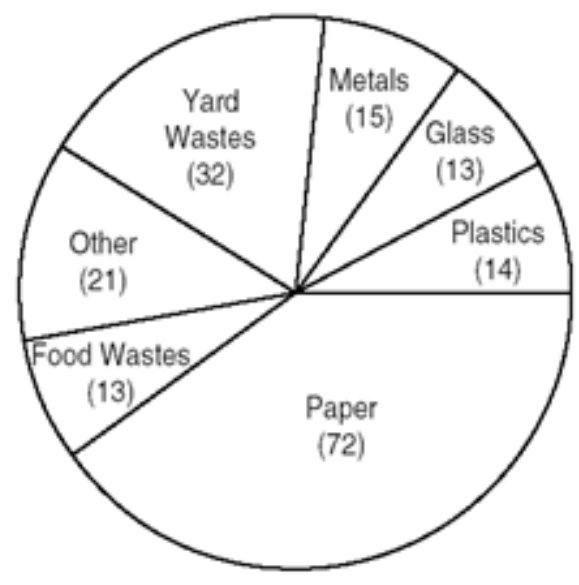

Total Weight $=180$ million tons

What percent of the total solid waste was paper?
A $25 \%$
B $33 \frac{1}{3} \%$
C $40 \%$
D $66 \frac{2}{3} \%$
E $72 \%$

Figure 3. Solid waste production in the U.S. 
Which of the following is the correct description of the graph of a quadratic function given by $f(x)=a x^{2}+b x+c, a \neq 0$ ?

A If $b^{2}-4 a c>0$ then the graph of the function intersects the $\mathrm{x}$-axis twice.

B If $b^{2}-4 a c<0$ then the graph of the function does not intersect the y-axis.

C If $b^{2}-4 a c=0$ then the graph does not intersect the $\mathrm{x}$-axis.

D If $\sqrt{b^{2}-4 a c}<0$ then the graph does not intersect the $\mathrm{x}$-axis.

Figure 4. Quadratic function mathematical problem 


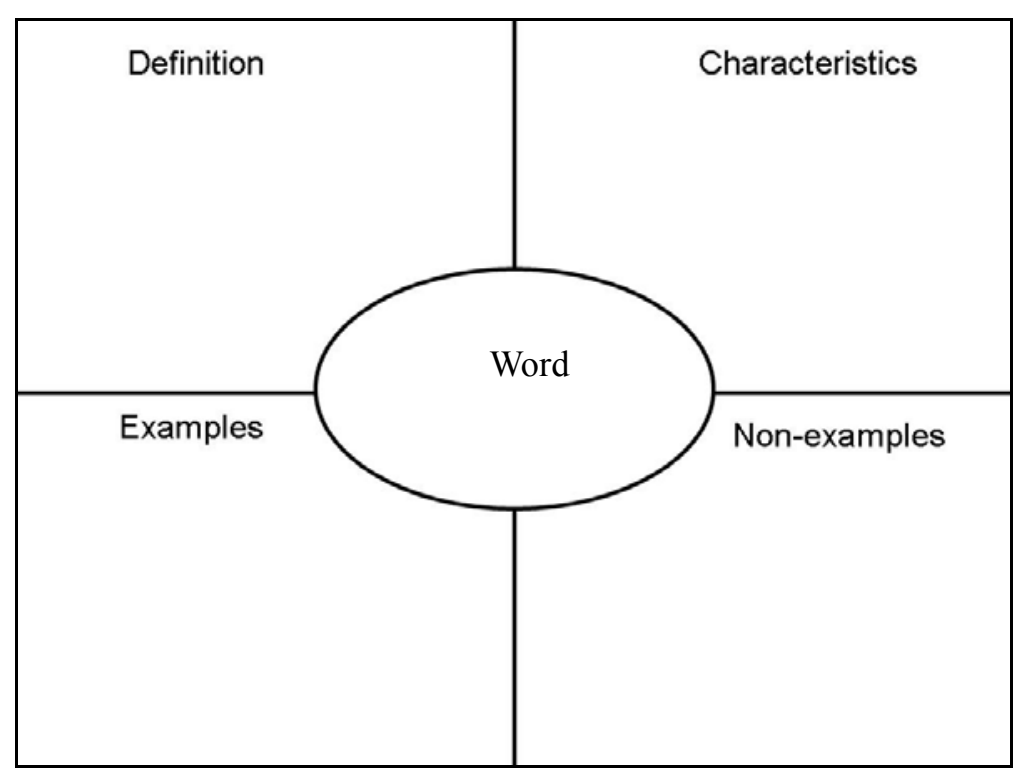

Figure 5. Frayer model. 


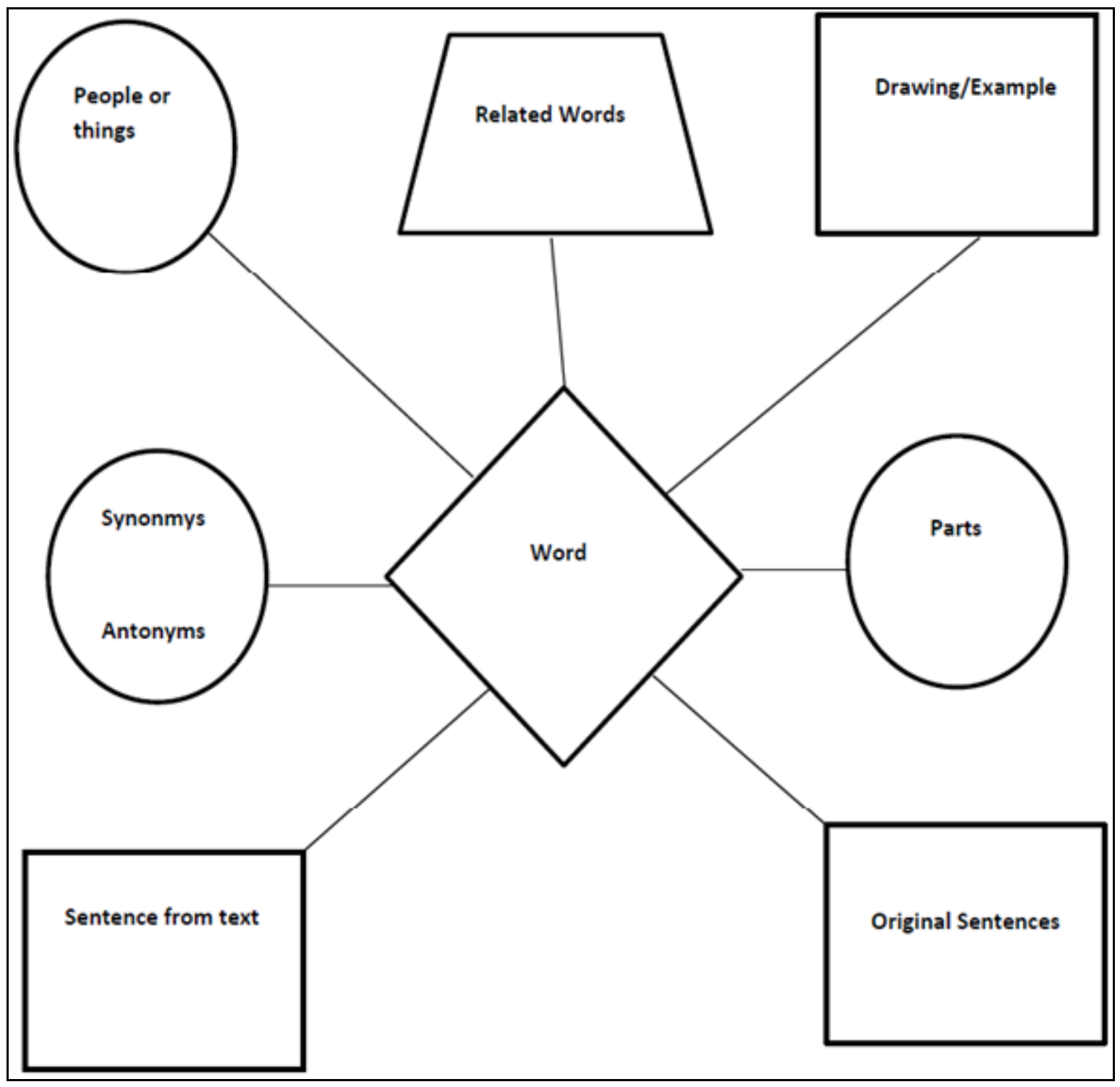

Figure 6. Vocabulary diagram. 